\title{
Magnetic resonance imaging and spectroscopy in evaluation of hypoxic ischemic encephalopathy in pediatric age group
}

\author{
Fatma Ibrahim Soliman Elshal ${ }^{1^{*}}$ (D) Walid Ahmed Elshehaby ${ }^{2}$, Mahmoud Abd elaziz Dawoud ${ }^{2}$ and \\ Ekhlas Abdelmonem Shaban²
}

\begin{abstract}
Background: Hypoxic ischemic encephalopathy is a major cause of pediatric mortality and morbidity, with possible long-term neurologic sequel, such as cerebral palsy. With improvements in care of at-risk neonates, more children survive. This makes it increasingly important to assess, soon after birth, the prognosis of children with hypoxicischemic encephalopathy. The aim of the study was to assess the additive role of magnetic resonance spectroscopy over conventional MRI in diagnosis and early prediction of pathological motor development in neonates with hypoxic ischemic encephalopathy.

Results: MRS ratios showed significant difference between unfavorable and normal outcome infants. MRS ratios as $\mathrm{Lac} / \mathrm{Cr}, \mathrm{NAA} / \mathrm{Cr}$ and NAA/Cho within basal ganglia, thalamus and white matter can significantly differentiate between patients with normal and pathological outcome at 1 year.

Lac/Cr positively correlates with the severity of HIE. Both NAA/Cr and NAA/Cho negatively correlate with the severity of the disease. Ratios cutoff values as Lac/Cr above 0.38 and 0.42 in basal ganglia and white matter, respectively, NAA/ Cr below 0.9 and 0.8 in basal ganglia and occipital white matter, respectively, and NAA/Cho below 0.29 and 0.31 in basal ganglia and frontal white matter, respectively, were significantly predictive of pathological outcome.

Conclusion: High Lac/Cr, low NAA/Cr and low NAA/Cho ratios within examined regions of the brain including deep grey matter nuclei as well as white matter are associated with an adverse outcome in infants with perinatal asphyxia. MRS is an accurate quantitative MR biomarker within the neonatal period for prediction of neurodevelopmental outcome after perinatal HIE. MRS may be useful in early clinical management decisions, and counseling parents thereby ensuring appropriate early intervention and rehabilitation.
\end{abstract}

Keywords: Magnetic resonance imaging, Spectroscopy, Hypoxic ischemic encephalopathy, Pediatric

\section{Background}

Perinatal asphyxia and consecutive hypoxic-ischemic encephalopathy (HIE) is a devastating condition that may lead to death or severe neurologic deficits in children such as cerebral palsy, mental retardation and epilepsy

\footnotetext{
*Correspondence: dr_fatma.radio@yahoo.com

${ }^{1}$ Radiology Department, Faculty of Medicine, Tanta University, El-geish

street, Tanta, Gharbya governorate, Egypt

Full list of author information is available at the end of the article
}

[1]. It affects more than two million newborns worldwide each year [2].

The pattern of brain injury is determined by how severe and long duration of hypoxia and degree of brain maturation [1].

Investigating HIE neurodevelopmental outcomes includes clinical neurological examination, serum biomarkers, neurophysiology and neuro-imaging modalities [3]. 
Conventional MRI shows brain morphology at a high resolution, superior to cerebral $\mathrm{CT}$ and ultrasound. MRI provides essential information for diagnosing the features of HIE. Advanced neuro-imaging modalities have attained a significant role in HIE workup [4].

T1WI could provide essential information for the diagnosis and identifying typical MRI features of hypoxic-ischemic injury [5]. The imaging pattern of HIE has been classified into three types [6]; parasagittal lesions, affecting cortico-subcortical regions, profound lesions located in the basal ganglia or thalamus, and multi-cystic encephalomalacia. It has been widely reported that the potential utility of proton MR Spectroscopy could reveal brain ischemic injuries in asphyxiated neonates earlier than T1- or T2-weighted MR imaging [7]. Proton magnetic resonance spectroscopy $\left({ }^{1} \mathrm{H}\right.$-MRS) is a quantitative, non-invasive tool used for identifying energy metabolism disturbances in the brain [8].

There is a wide range of H-MRS derived metabolites were suggested as potential biomarkers, e.g. some studies concluded that absolute Lac levels and/ or Lac containing metabolite ratios (Lac/NAA, Lac/ Cho, $\mathrm{Lac} / \mathrm{Cr}$ ) were the most accurate in prediction of outcome [9-11], while other showed that NAA/Cr, NAA/Cho, absolute NAA and/or Cho levels had promising prognostic powers $[9,10]$, but only few studies investigating glutamate $(\mathrm{Glx})$ or glutamate-containing metabolite ratios $(\mathrm{Glx} / \mathrm{Cr})$ [2].

MRS measures concentrations of these cerebral metabolites to elucidate derangements in aerobic metabolism [7].

MRS can also detect impairment of neuronal functions which are caused by HIE. Moreover, $1 \mathrm{H}-\mathrm{MRS}$ gives a good simultaneous imaging data from the cortex, basal ganglia and white matter [12].

Studies have suggested that MRS of brain metabolites may serve as a suitable tool for earlier diagnosis of HIE compared to conventional MRI and prognostication and may guide future therapies in time $[8,11,13]$.

The aim of the study was to assess the additive role of magnetic resonance spectroscopy over conventional MRI in diagnosis and early prediction of pathological motor development in neonates with hypoxicischemic encephalopathy.

\section{Methods}

\section{Patients population}

This prospective study was carried out on 30 newly born infants, 24 full term and 6 preterm, 14 males and 16 females, their ages ranged from 6 to 60 days who clinically suspected to suffer from hypoxic-ischemic encephalopathy. The duration of this study was one year starting from November 2019 to December 2020.

Approval of Research Ethics Committee (REC) and informed consent were obtained from all guardiancies of patients participating in this study after explanation of the benefits and risks of the procedure. Privacy and confidentiality of all patients' data were guaranteed. All data provision was monitored and used for scientific purpose only.

The included patients were neonates who exposed to perinatal hypoxic conditions based on history of difficult or prolonged labor, placenta previa, cord prolapse and/ or severe hemorrhage. Exclusion criteria included infants of consanguineous marriage, neonates who had cardiac or brain anomalies, neonates who exposed to intrauterine infection, neonates suffered from metabolic disorders, neonates born to drug addict mother, neonates with suspected neonatal sepsis, traumatic birth injuries and kernicterus.

\section{All the included participants were subjected to the following: \\ Data collection}

- Complete history taking: all medical records of all patients were reviewed with specific attention to the perinatal history and delivery circumstances.

- Complete clinical examination: general examination was done to all patients including pulse, $\mathrm{O} 2$ saturation, blood pressure and temperature. All patients were classified clinically according to Sarnat and Sarnat grading system into stage I, stage II, and stage III HIE. Sarnat and Sarnat described their grading system in 1976 in a study relating electroencephalographic finding to the clinical condition of the infant and classified neonates with HIE into three stages: stage I (mild), stage II (moderate) and stage III (severe) HIE [14].

- Routine Laboratory investigations included complete blood picture, serum electrolytes ( $\mathrm{Na}, \mathrm{K}$ and calcium), arterial blood gases analysis and renal function test.

\footnotetext{
(See figure on next page.)

Fig. 1 A 2-month-old male patient weighted 3 kg presented clinically by respiratory distress (sarnat stage II-III). Conventional MRI (A, B) Axial T2 flair images show high signal intensity in periventricular area (PVL) (red arrows), absent PLIC signal denoting poor myelination (black arrow), Indistinct grey white matter differentiation (blue arrows). Multivoxel MRS (C) and Spectrum (D) long TE 144 show decreased NAA peak with increased of CHO peak, also Multivoxel MRS (E) and spectrum (F) short TE 35 show marked increased lac peak. Lac/Cr at basal ganglia \& thalamus ratio 3.67 Lac/ $\mathrm{Cr}>1.5$ indicating severe HIE (grade III). Outcome..... Atonic cerebral palsy..... Died.
} 

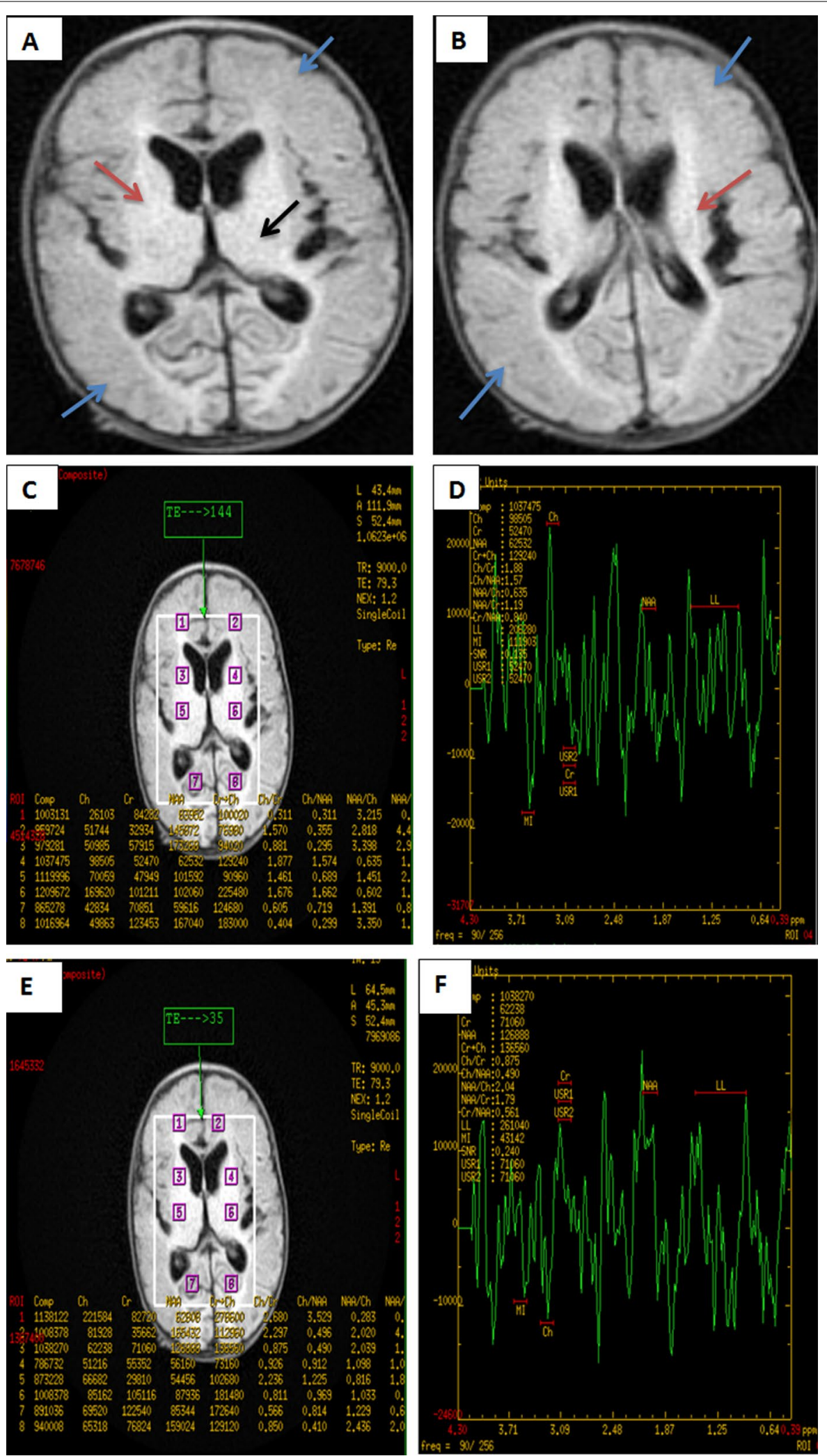

Fig. 1 (See legend on previous page.) 


\section{Radiological examination}

MRI examinations were performed by using General Electric, 1.5 tesla system (signal high speed, GE medical systems).

All patients' guardiancies were informed about the MRI magnets, approximate duration of MRI and MRS techniques. The examination was done during natural sleep in 6 neonates and by sedation in 24 neonates using Chloral hydrate in a dose of $50 \mathrm{mg} / \mathrm{kg}$ body weight.

All the patients were examined in a supine position with use of a standard head coil and immobilized in a comfortable position.

All neonates were studied with a 1.5-T whole body MR imager equipped with high-performance gradients, using a manufacturer supplied quadrate head coil.

Routine sequences performed in all participants Magnetic resonance imaging (MRI) including Sagittal T2-weighted (300/14/1[TR/TE/excitations]), Axial fast spin echo T2-weighted (3000/91/1), Axial fast fluid attenuation inversion recovery (FLAIR) (10002/172/1, T1 2.2s), Axial T1-weighted (500/14/1) and diffusion-weighted images (DWI) was performed with an axial single shot echoplanar spin-echo sequence (TR/TE: 10000/89.999.3).

In general, all axial sequences used $5 \mathrm{~mm}$ thickness with intersection gap of $2.5 \mathrm{~mm}$, a $256 \times 192$ matrix, the same imaging angle along orbitomeatal line and a 22 or $24 \mathrm{~cm}$ field of view.

In magnetic resonance spectroscopy (MRS), Axial FLAIR imaging was used for voxels localization. Grid measured $16 \times 16$ was applied; only 8 separate voxels were individual placed in four regions of interest at both sides; the frontal and parieto-occipital white matter, thalamus and basal ganglia bilaterally. A voxel size of $1.5 \times 1.5 \times 1.5 \mathrm{~cm}^{3}$ to $2 \times 2 \times 2 \mathrm{~cm}^{3}$ was used. Contact with the cerebrospinal fluid and skull bone was avoided.

Frontal voxels encompassed cortex medially at the level of the anterior interhemispheric fissure, and voxels placed within parieto-occipital subcortical white matter encompassed cortex of the medial occipital lobe and parietal lobe. Typical acquisition time was 5 min $4 \mathrm{~s}$ per spectral acquisition $20 \mathrm{~min}$ for all.

Localization tool was used which is known as spectroscopic imaging (MRSI) or chemical shift imaging (CSI); this method overcomes the poorer quality due to the greater magnetic field inhomogeneities that occur over the larger volume in (MVS).

Localized shimming, phase correction, water suppression calibration and scan acquisition to eliminate artifacts caused by eddy currents were performed prior to acquisition of the spectra.

The pulse sequence used was point resolved spectroscopy (PRESS) with parameters; long TE (TR/ $\mathrm{TE}=2000 / 144 \mathrm{~ms})$ and short $\mathrm{TE}(\mathrm{TR} / \mathrm{TE}=2000 / 35 \mathrm{~ms})$.

Long TE was used to clearly visualize intensity peak of $\mathrm{NAA}, \mathrm{Cho}$ and $\mathrm{Cr}$ and to calculate NAA/Cr, NAA/Cho and $\mathrm{Cho} / \mathrm{Cr}$ ratios. Short TE was mainly used to illustrate Lac peak and to calculate $\mathrm{Lac} / \mathrm{Cr}$ ratio.

Data were post-processed at GE Advantage workstation provided by the magnitude spectra processed automatically by baseline correction and curve-fitting procedures to determine the resonance areas of various metabolites.

Image interpretation: reporting MRI and MRS images were done by two conjoined neuro-radiologists with inter observer agreement (MD, 35 years of experience and ES, 15 years of experience) blinded to clinical data.

\section{Patients' follow up}

Sensorineural and psychomotor integrity of patients was assessed clinically by using Bayley Scales of Infant and Toddler Development, $3^{\text {rd }}$ edition (Bayley III scale) [15].

\section{Statistical analysis}

Statistical analysis and presentation of data were conducted using SPSS version 22 computer program. All numerical variables were checked for normality by Shapiro-Wilk test. Normally distributed numerical variables were presented as mean $\pm \mathrm{SD}$, and differences between two groups were tested using independent T-test, whereas differences between three groups were analyzed by the one-way ANOVA test. When results of ANOVA were significant, post hoc Games-Howell test was performed for pairwise comparison of each two groups. Categorical variables were summarized as frequencies and percentages, and association between variables was tested using X2 tests (Pearson's Chi-square for independence or Fisher Exact Tests as appropriate). Furthermore, Receiver operating characteristics (ROC) curve analysis was carried out to test the discrimination power of the studied ratios to predict the outcomes. Areas under the

(See figure on next page.)

Fig. 2 A 20-days-old female patient weighted $2750 \mathrm{gm}$ presented clinically by respiratory distress-Sarnat stage II. Conventional MRI Axial T1WI (A, B) shows rim of high signal intensities (germinal matrix hemorrhage) in the left occipital horn and adjacent to the frontal horn of lateral ventricle (red arrows). Axial T2WI (C) shows dilatation of the ventricular system (black arrow) and dilatation of subarachnoid spaces (central and peripheral atrophic changes) (blue arrows), indistinct grey white matter differentiation (green arrows). Multivoxel MRS (D) and MRS Spectrum (E) long TE 144 show decreased NAA peak, and increased CHO peak also Multivoxel MRS (F) and spectrum $(\mathbf{G})$ short TE 35 show marked increased lac peak. Lac/Cr at basal ganglia \& thalamus ratio 2.7 denoting marked stage of HIE (grade III). Outcome: Cerebral palsy 

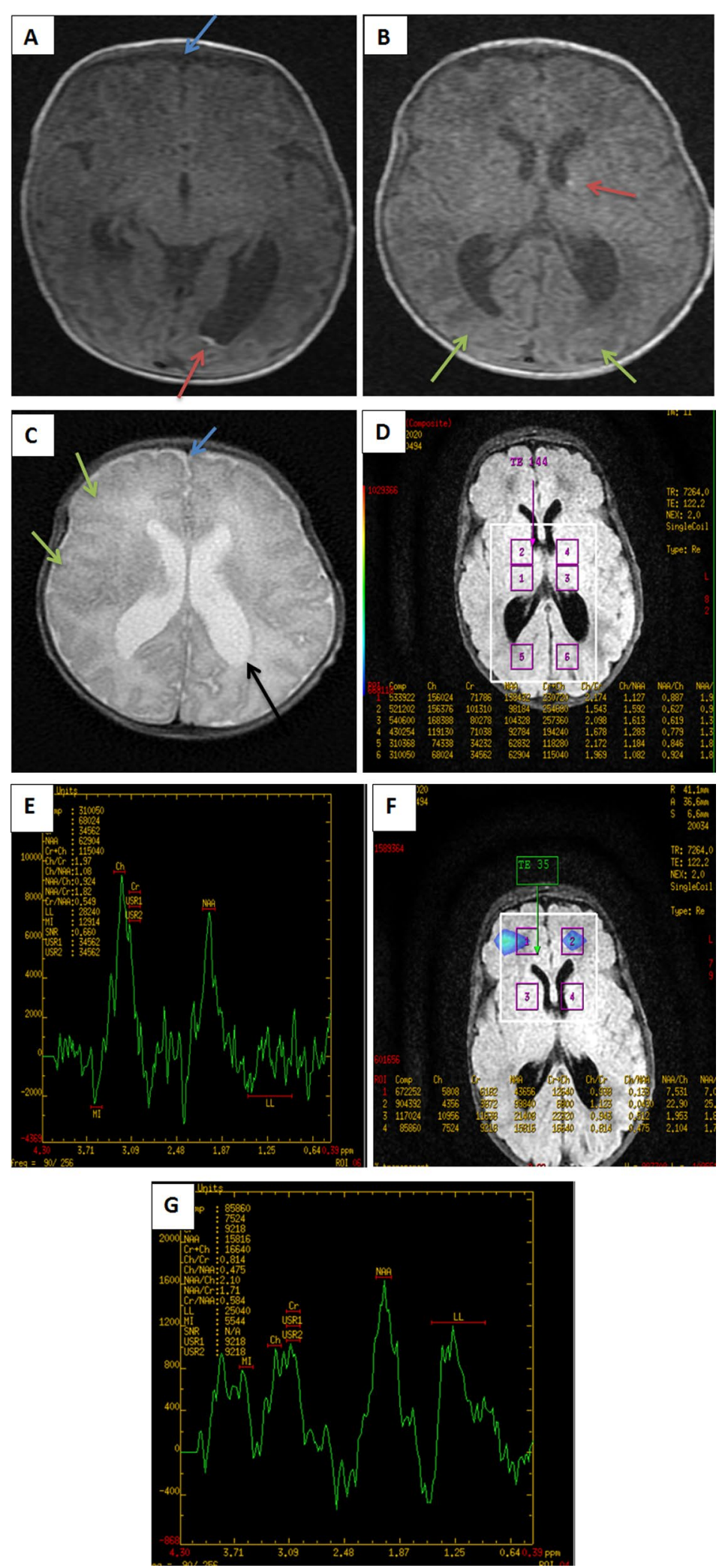

Fig. 2 (See legend on previous page.) 
ROC curves, sensitivity, specificity, and accuracy were calculated. A $p$-value of $<0.05$ was considered statistically significant.

\section{Results}

The study included 30 neonates; 14 (46.7\%) were males while the remaining $16(53.3 \%)$ were females. The age at the time of MRI examination was ranging from 6 to 60 day (median, 23 days). The majority of cases (73.3\%) were in the age group ranging from $10-<30$ days. The average weight was $2250-4400 \mathrm{~g}$ (mean, $3243 \pm 684 \mathrm{~g}$ ). There were $53.4 \%$ of the examined neonates in the weight group ranging from 2 to $<3 \mathrm{~kg}$. Among the examined neonates $60 \%$ were born by caesarian section and $40 \%$ were delivered vaginally.

Among the studied neonates, 6 cases $(20 \%)$ were classified as Sarnat stage I, 10 cases (33.3\%) were Sarnat stage II, while the remaining 14 cases $(46.7 \%)$ were Sarnat stage III HIE.

Among the examined neonates, MRI was normal in 16 cases (53.3\%). The remaining 14 cases showed multiple findings, reduced myelination was identified in $20 \%$ of studied cases, and brain edema was found in $16.6 \%$ of studied cases. Each of periventricular leukomalacia, ventriculomegaly, white matter injury, intra-cerebral hematoma occurred in $13.3 \%$ of examined neonates. Also each of germinal matrix hemorrhage and brain atrophy was detected in $6.7 \%$ of studied neonates (Table 1).

Group III shows the highest incidence of poor outcome ( 2 cases died, 10 developed cerebral palsy and 2 cases had delayed motor development); In group II there were 2 cases with cerebral palsy and 4 cases of delayed development while all cases of group I whose the least $\mathrm{Lac} / \mathrm{Cr}$ ratio were normal in follow-up (Table 2).

All of the examined neonates demonstrated lactate peak in MRS examination. However there were significant differences between infants with mild, moderate and severe stages of HIE.

$\mathrm{Lac} / \mathrm{Cr}$ ratio in basal ganglia was $0.19 \pm 0.02$, $0.83 \pm 0.42,2.79 \pm 0.33$ in stages I, II, and III, respectively. The difference in $\mathrm{Lac} / \mathrm{Cr}$ ratio between three stages of HIE was statistically significant $(P \leq 0.001)$. Also stage III had significantly higher Lac/Cr ratio than stages I and II $(P=0.003,<0.001$ and $<0.001)$ (Figs. $1,2,3)$.

$\mathrm{Lac} / \mathrm{Cr}$ in occipital white matter was $0.25 \pm 0.09$, $0.9 \pm 0.49,3.09 \pm 0.45$ in stages I, II, and III, respectively. The difference in $\mathrm{Lac} / \mathrm{Cr}$ ratio between three stages of
HIE was statistically significant $(P \leq 0.001)$. Also stage III had significantly higher $\mathrm{Lac} / \mathrm{Cr}$ ratio than stages I and II $(P=0.005,<0.001$ and $<0.001)$.

$\mathrm{NAA} / \mathrm{Cr}$ in basal ganglia in HIE stages I, II and III were $1.06 \pm 0.01,0.84 \pm 0.10$, and $0.56 \pm 0.04$, respectively. The difference in NAA/Cr ratio between three stages of HIE was statistically significant $(P \leq 0.001)$. Also stage III had significantly lower NAA/Cr ratio than HIE stages I and II $(P \leq 0.001,<0.001$ and $<0.001)$.

NAA/Cr in frontal white matter in HIE stages I, II and III were $1.10 \pm 0.02,0.83 \pm 0.17$, and $0.57 \pm 0.04$, respectively. The difference in NAA/Cr ratio between three stages of HIE was statistically significant $(P \leq 0.001)$. Also stage III had significantly lower NAA/Cr ratio than HIE stages I and II $(P=0.002,<0.001$ and 0.002$)$.

NAA/Cho in basal ganglia in HIE stages I, II and III were $0.39 \pm 0.02,0.3 \pm 0.05$ and $0.17 \pm 0.03$. The difference in NAA/Cho ratio between three stages of HIE was statistically significant $(P \leq 0.001)$. Also stage III had significantly lower NAA/Cho ratio than stages I and II $(P \leq 0.001,<0.001$ and $<0.001)$.

NAA/Cho in frontal white matter in HIE stages I, II and III were $0.41 \pm 0.01,0.31 \pm 0.04$ and $0.18 \pm 0.03$. The difference in NAA/Cho ratio between three stages of HIE was statistically significant $(P \leq 0.001)$. Also stage III had significantly lower NAA/Cho ratio than HIE stages I and II $(P \leq 0.001,<0.001$ and $<0.001)$.

$\mathrm{Cho} / \mathrm{Cr}$ in basal ganglia, thalamus, frontal and occipital white matter was statistically insignificant in differentiating between the three stages of HIE.

Each of Lac/Cr, NAA/Cr within basal ganglia, frontal and occipital white matter were significant in differentiating neonates with normal and poor outcomes at 1 year $(P \leq 0.001$ and $<0.001)$.

Although normal neonatal MRS usually reveals mildly elevated choline and reduced NAA due to incomplete myelination process, yet significant difference was also noted regarding NAA/choline ratio within frontal and occipital white matter, basal ganglia between infants who had poor outcome, and those with normal outcome $(P=0.001)$.

$\mathrm{Cho} / \mathrm{Cr}$ ratio within basal ganglia and white matter was statistically insignificant in differentiating between neonates with normal and poor outcomes. As regarding (Tables 3, 4).

ROC curve analysis revealed that $\mathrm{Lac} / \mathrm{Cr}$ ratio higher than $0.38,0.36,0.42$ in basal ganglia, thalamus and white

(See figure on next page.)

Fig. 3 A 15-days-old female patient weighted 3 kg presented clinically by respiratory distress sarnat stage I. Conventional MRI Axial T1WI Flair (A), Axial T2WI (B): normal progress of myelination according to age (preserved T1 high signal intensity of PLIC) (red arrow), no abnormal signal in basal ganglia and thalamus, distinct grey white matter differentiation (blue arrows), prominent subarachnoid spaces (green arrows). Multivoxel MRS (C) and Spectrum (D) long TE 144 show decreased NAA peak and increased CHO also Multivoxel MRS (E) and spectrum (F) short TE 35 show increased lac peak. Lac/Cr at basal ganglia \& thalamus ratio 0.65 denoting moderate stage HIE (grade II). Outcome: delayed motor development 

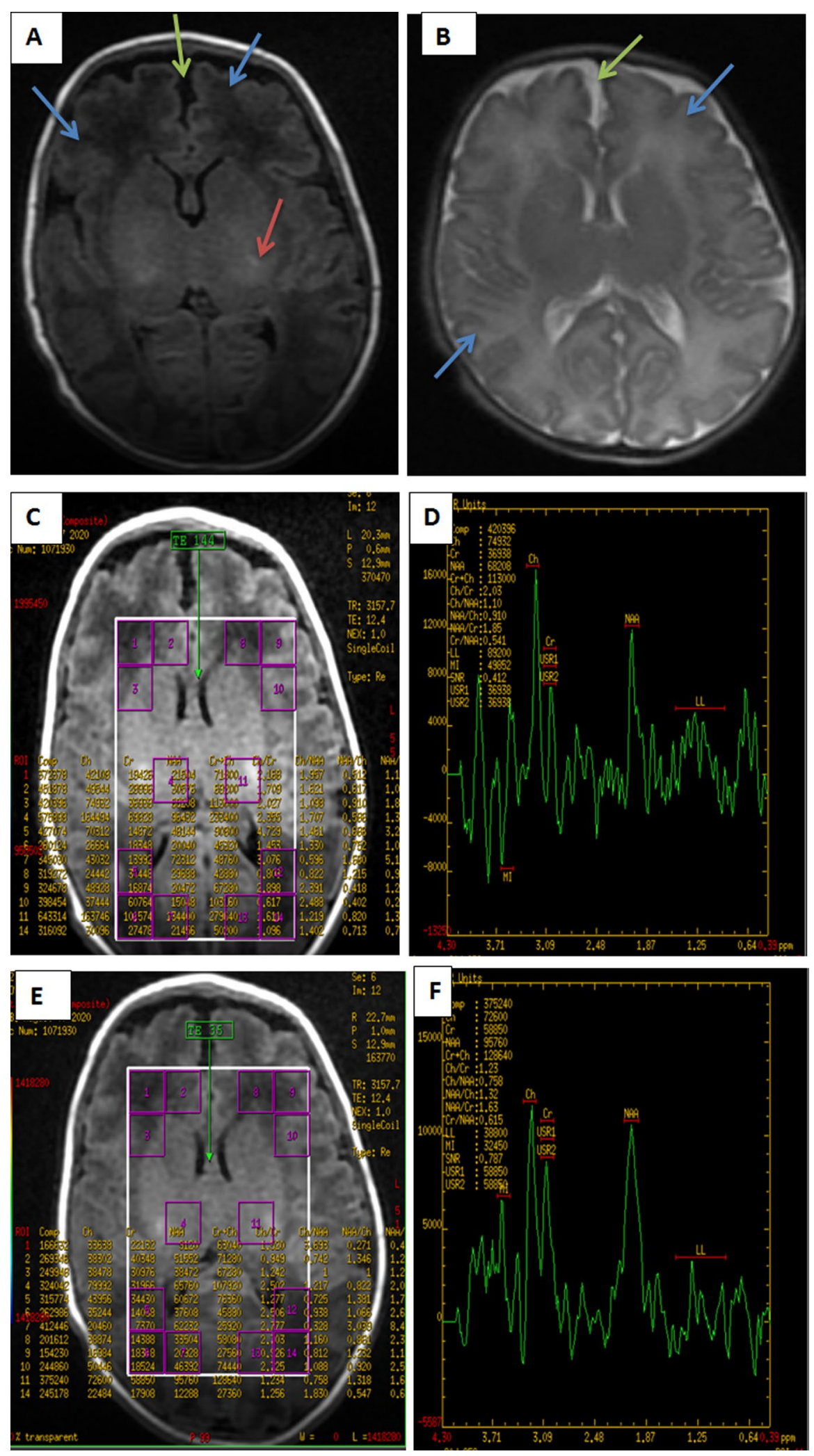

Fig. 3 (See legend on previous page.) 
Table $1 \mathrm{MRI}$ findings in the studied patients

\begin{tabular}{lll}
\hline MRI finding & No & \% \\
\hline Normal & 16 & $53.3 \%$ \\
Periventricular leukomalacia & 4 & $13.3 \%$ \\
Germinal matrix hemorrhage & 2 & $6.7 \%$ \\
Ventriculomegaly & 4 & $13.3 \%$ \\
White matter injury & 4 & $13.3 \%$ \\
Intracerebral hematoma & 4 & $13.3 \%$ \\
Reduced myelination & 6 & $20 \%$ \\
Brain edema & 5 & $16.7 \%$ \\
Atrophy & 2 & $6.7 \%$ \\
\hline
\end{tabular}

Table 2 Relation between MRS grading and patients' outcome

\begin{tabular}{llll}
\hline & \multicolumn{2}{l}{ Grading } & \\
\cline { 2 - 4 } & I & II & III \\
\hline Death & 0 & 0 & 2 \\
Cerebral palsy & 0 & 2 & 10 \\
Developmental delay & 0 & 4 & 2 \\
Normal & 10 & 0 & 0 \\
\hline
\end{tabular}

matter can significantly differentiate cases with poor outcome as regard.

$\mathrm{NAA} / \mathrm{Cr}$ ratio lower than $0.9,0.75,0.9,0.8$ in basal ganglia, thalamus, frontal and occipital NAA/Cho ratio lower than $0.29,0.25,0.31,0.3$ in basal ganglia, thalamus, frontal and occipital white matter can significantly differentiate cases with poor outcome (Table 5).

\section{Discussion}

Perinatal hypoxia is a vital cause of long-term neurologic complications ranging from mild behavioral deficits to intractable seizures, mental retardation, and cerebral palsy. With improvements in care of at-risk neonates, more and more children survive. This makes it increasingly important to assess, soon after birth, the prognosis of children with hypoxic-ischemic encephalopathy [16].

Magnetic resonance imaging (MRI) is a leading source of brain injury biomarkers in perinatal HIE. Different patterns of brain injury by conventional MRI have been related to severity and phenotype of neurodevelopmental sequel after HIE. However, conventional MRI requires availability of an experienced pediatric neuro radiologist, can be subjective, and provides broad severity classification on an ordinal scale [17]. Quantitative MRI techniques such as MRS can

Table 3 Comparison of the studied ratios at various studied sites according to Sarnat staging

\begin{tabular}{|c|c|c|c|c|c|c|c|c|c|c|c|}
\hline & & \multicolumn{3}{|c|}{ HIE staging } & \multicolumn{3}{|c|}{ One -Way ANOVA } & \multirow[b]{2}{*}{ P2 } & & \multirow[b]{2}{*}{ P3 } & \\
\hline & & Stage I & Stage II & Stage III & $\mathrm{F}$ & $P$ value & P1 & & & & \\
\hline \multicolumn{12}{|l|}{ Basal ganglia } \\
\hline lac/Cr ratio & Mean $\pm S D$ & $0.19 \pm .02$ & $0.83 \pm .42$ & $2.79 \pm .33$ & 406.87 & $<0.001^{*}$ & $0.003^{*}$ & $<0.001^{*}$ & & $<0.001^{*}$ & \\
\hline NAA/Cr ratio & Mean $\pm S D$ & $1.06 \pm .01$ & $0.84 \pm .10$ & $0.56 \pm .04$ & 975.09 & $<0.001^{*}$ & $<0.001^{*}$ & $<0.001^{*}$ & & $<0.001^{*}$ & \\
\hline NAA/Cho ratio & Mean \pm SD & $0.39 \pm .02$ & $0.3 \pm .05$ & $0.17 \pm .03$ & 159.43 & $<0.001^{*}$ & $<0.001^{*}$ & $<0.001^{*}$ & & $<0.001^{*}$ & \\
\hline Cho/Cr ratio & Mean \pm SD & $2.92 \pm .34$ & $2.94 \pm .23$ & $3.15 \pm .26$ & 2.77 & 0.101 & Not applic & able & & & \\
\hline \multicolumn{12}{|l|}{ Thalamus } \\
\hline lac/Cr ratio & Mean $\pm S D$ & $0.2 \pm .04$ & $0.92 \pm .49$ & $3.04 \pm .50$ & 223.76 & $<0.001^{*}$ & $0.003^{*}$ & $<0.001^{*}$ & & $<0.001^{*}$ & \\
\hline NAA/Cr ratio & Mean $\pm S D$ & $1.07 \pm .01$ & $0.84 \pm .11$ & $0.56 \pm .05$ & 640.92 & $<0.001^{*}$ & $<0.001^{*}$ & $<0.001^{*}$ & & $<0.001^{*}$ & \\
\hline NAA/Cho ratio & Mean $\pm S D$ & $0.4 \pm .01$ & $0.28 \pm .03$ & $0.18 \pm .02$ & 351.74 & $<0.001^{*}$ & $<0.001^{*}$ & $<0.001^{*}$ & & $<0.001^{*}$ & \\
\hline Cho/Cr ratio & Mean $\pm S D$ & $2.88 \pm .31$ & $2.91 \pm .23$ & $3.15 \pm .26$ & 3.34 & 0.068 & Not applic & able & & & \\
\hline \multicolumn{12}{|l|}{ Frontal WM } \\
\hline lac/Cr ratio & Mean $\pm S D$ & $0.18 \pm .03$ & $0.97 \pm .49$ & $2.94 \pm .38$ & 358.51 & $<0.001^{*}$ & $0.002^{*}$ & & $<0.001^{*}$ & $<0.001^{*}$ & \\
\hline NAA/Cr ratio & Mean $\pm S D$ & $1.10 \pm .02$ & $0.83 \pm .17$ & $0.57 \pm .04$ & 765.59 & $<0.001^{*}$ & $0.002^{*}$ & & $<0.001^{*}$ & $0.002^{*}$ & \\
\hline NAA/Cho ratio & Mean $\pm S D$ & $0.41 \pm .01$ & $0.31 \pm .04$ & $0.18 \pm .03$ & 228.16 & $<0.001^{*}$ & $<0.001^{*}$ & & $<0.001^{*}$ & $<0.001^{*}$ & \\
\hline Cho/Cr ratio & Mean $\pm S D$ & $2.87 \pm .30$ & $2.91 \pm .22$ & $3.08 \pm .17$ & 2.92 & 0.095 & Not applic & able & & & \\
\hline \multicolumn{12}{|l|}{ Occipital WM } \\
\hline lac/Cr ratio & Mean $\pm S D$ & $0.25 \pm .09$ & $0.9 \pm .49$ & $3.09 \pm .45$ & 249.05 & $<0.001^{*}$ & $0.005^{*}$ & & $<0.001^{*}$ & & $<0.001^{*}$ \\
\hline NAA/Cr ratio & Mean $\pm S D$ & $1.11 \pm .02$ & $0.82 \pm .09$ & $0.46 \pm .01$ & 2871.11 & $<0.001^{*}$ & $<0.001^{*}$ & & $<0.001^{*}$ & & $<0.001^{*}$ \\
\hline NAA/Cho ratio & Mean $\pm S D$ & $0.4 \pm .02$ & $0.31 \pm .02$ & $0.17 \pm .03$ & 184.80 & $<0.001^{*}$ & $<0.001^{*}$ & & $<0.001^{*}$ & & $<0.001^{*}$ \\
\hline Cho/Cr ratio & Mean $\pm S D$ & $3.03 \pm .29$ & $3.04 \pm .20$ & $3.15 \pm .26$ & .858 & 0.447 & Not applic & able & & & \\
\hline
\end{tabular}

* Significant at $p<0.05$ 
Table 4 Comparison between patients with favorable and unfavorable outcomes regarding the studied ratios at the various studied sites

\begin{tabular}{|c|c|c|c|c|c|}
\hline & & Outcome & & & \\
\hline & & $\begin{array}{l}\text { Favorable } \\
\mathrm{N}=10\end{array}$ & $\begin{array}{l}\text { Unfavorable } \\
\mathrm{N}=20\end{array}$ & $\mathbf{T}$ & $P$ value \\
\hline sal ganglia & & & & & \\
\hline lac/Cr ratio & Mean $\pm S D$ & $0.26 \pm .09$ & $2.29 \pm .82$ & 10.96 & $<0.001^{*}$ \\
\hline $\begin{array}{l}\mathrm{NAA} / \mathrm{Cr} \\
\text { ratio }\end{array}$ & Mean $\pm S D$ & $1.02 \pm .07$ & $0.62 \pm .11$ & 10.92 & $<0.001^{*}$ \\
\hline $\begin{array}{l}\mathrm{NAA} / \mathrm{CHO} \\
\text { ratio }\end{array}$ & Mean $\pm S D$ & $0.37 \pm .03$ & $0.2 \pm .05$ & 9.64 & $<0.001^{*}$ \\
\hline $\begin{array}{c}\mathrm{CHO} / \mathrm{Cr} \\
\text { ratio }\end{array}$ & Mean $\pm S D$ & $2.90 \pm .31$ & $3.09 \pm .25$ & 1.82 & 0.079 \\
\hline Thalamus & & & & & \\
\hline $\mathrm{Lac} / \mathrm{Cr}$ ratio & Mean \pm SD & $0.26 \pm .08$ & $2.51 \pm .92$ & 7.64 & $<0.001^{*}$ \\
\hline $\begin{array}{l}\mathrm{NAA} / \mathrm{Cr} \\
\text { ratio }\end{array}$ & Mean \pm SD & $1.03 \pm .06$ & $0.62 \pm .10$ & 13.56 & $<0.001^{*}$ \\
\hline $\begin{array}{l}\mathrm{NAA} / \mathrm{CHO} \\
\text { ratio }\end{array}$ & Mean \pm SD & $0.35 \pm .06$ & $0.21 \pm .05$ & 7.26 & $<0.001^{*}$ \\
\hline $\begin{array}{c}\mathrm{CHO} / \mathrm{Cr} \\
\text { ratio }\end{array}$ & Mean $\pm S D$ & $2.91 \pm .28$ & $3.07 \pm .27$ & 1.45 & 0.158 \\
\hline Frontal WM & & & & & \\
\hline Lac/Cr ratio & Mean $\pm S D$ & $0.27 \pm .12$ & $2.47 \pm .82$ & 11.75 & $<0.001^{*}$ \\
\hline $\begin{array}{l}\mathrm{NAA} / \mathrm{Cr} \\
\text { ratio }\end{array}$ & Mean \pm SD & $1.07 \pm .04$ & $0.61 \pm .07$ & 19.08 & $<0.001^{*}$ \\
\hline $\begin{array}{l}\mathrm{NAA} / \mathrm{CHO} \\
\text { ratio }\end{array}$ & Mean \pm SD & $0.39 \pm .04$ & $0.21 \pm .06$ & 8.54 & $<0.001^{*}$ \\
\hline $\begin{array}{c}\mathrm{CHO} / \mathrm{Cr} \\
\text { ratio }\end{array}$ & Mean \pm SD & $2.90 \pm .28$ & $3.02 \pm .20$ & 1.41 & 0.169 \\
\hline Occipital WI & & & & & \\
\hline Lac/Cr ratio & Mean \pm SD & $0.29 \pm .08$ & $2.54 \pm .93$ & 10.80 & $<0.001^{*}$ \\
\hline $\begin{array}{l}\mathrm{NAA} / \mathrm{Cr} \\
\text { ratio }\end{array}$ & Mean \pm SD & $1.04 \pm .09$ & $0.55 \pm .14$ & 10.0 & $<0.001^{*}$ \\
\hline $\begin{array}{l}\mathrm{NAA} / \mathrm{CHO} \\
\text { ratio }\end{array}$ & Mean $\pm S D$ & $0.37 \pm .04$ & $0.21 \pm .06$ & 9.25 & $<0.001^{*}$ \\
\hline $\begin{array}{c}\mathrm{CHO} / \mathrm{Cr} \\
\text { ratio }\end{array}$ & Mean \pm SD & $3.05 \pm .26$ & $3.10 \pm .24$ & 0.509 & 0.615 \\
\hline
\end{tabular}

*Significant at $p<0.05$

overcome these limitations by providing continuous, reproducible measures of brain microstructural and metabolic injury [7].

MRS outperforms MRI in detecting abnormalities of metabolism even when normal structures are present on magnetic resonance (MR) imaging studies. Therefore, combination of MR studies and 1 HMRS may make it possible to evaluate severity and help predicting outcome of HIE [18].

MRI examination was normal in nearly half of the patients (16 cases) (all had lac peak on MRS examination), the remaining 14 cases showed multiple abnormalities as periventricular leukomalacia (PVL) and ventriculomegaly, reduced myelination (absent of high signal intensity of PLIC in T1WI), white matter injury displaying hypo intensity signal in T1WI and hyper intensity in T2WI, germinal matrix hemorrhage, brain atrophy, and smudged grey white matter differentiation (brain edema). These findings are in agreement with Zhu et al. [19] who examined 31 neonates with HIE classified in 3 groups underwent follow-up MRI. All patients in group I died. In group II (moderate HIE), the abnormalities observed in the brains of patients included extensive extracerebral spaces and encephalatrophy, cerebral infarction, focal encephalomalacia and encephalatrophy, multiple cyst-like encephalomalacia, marble-like basal ganglia, periventricular leukomalacia, myelin hypoevolutism, gliosis, and thinning of corpus callosum. In group III, normal or slightly extensive extracerebral spaces were observed. For 11 cases in group III, MRI detected slightly extensive extracerebral spaces in 2 cases. The MRI examination was normal in 9 cases. Also in the study of Guo et al. [4] out of the total of 29 cases, 13 cases had no MRI abnormalities; 10 had minor to moderate abnormalities; 4 cases had severe abnormalities; with two mortality cases (one after 6 days and one after 12 days).

Patients were classified by MRS into 3 groups according to the value of $\mathrm{Lac} / \mathrm{Cr}$ ratio; Group I had Lac/Cr lower than 0.5 , Group II in which $\mathrm{Lac} / \mathrm{Cr}$ ranging between 0.5 and 1.5 and Group III in which $\mathrm{Lac} / \mathrm{Cr}$ ratio was higher than 1.5 .

It was found that $\mathrm{Lac} / \mathrm{Cr}$ ratio positively correlates with clinical staging, severity of brain abnormalities in MRI examination and patients' outcome on neurological examination at 1 year so it promotes worse prognosis. As in group III with the highest $\mathrm{Lac} / \mathrm{Cr}$ ratio which included 14 patients all from stage III Sarnat, highest incidence of brain abnormalities on MRI examination and the worst prognosis ( 2 cases died, 10 cases developed cerebral palsy and 2 cases had delayed development), in group II which included 6 patients all from Sarnat II stage showing normal MRI examination, 4 cases had developmental delay and 2 cases had cerebral palsy, but in group I included 10 patients (6 patients were clinically classified as Sarnat stage I and 4 patients as Sarnat stage II) all of them had normal neurological examination on follow-up.

These results are in agreement with the Egyptian study Noaman et al. [20] who studied the role of MRS and chemical biomarkers in grading and assessing the severity and prognosis of HIE non-invasively in 30 newborn with HIE (15 stage I Sarnat, 11 stage II Sarnat, 4 stage III Sarnat) and concluded that $\mathrm{Lac} / \mathrm{Cr}$ was a good indicator in recognition of the outcome as in the group whom Lac/ $\mathrm{Cr}$ greater than 1.5 severe clinical symptoms and signs (Sarnat stage III) were present and then all neonates were died. 
Table 5 Diagnostic performance of the studied ratios for the outcome of patients by ROC curve analysis

\begin{tabular}{|c|c|c|c|c|c|c|}
\hline & Cutoff & $\begin{array}{l}\text { Sensitivity \% } \\
(95 \% \mathrm{CI})\end{array}$ & $\begin{array}{l}\text { Specificity \% } \\
(95 \% \mathrm{Cl})\end{array}$ & AUC & $95 \% \mathrm{Cl}$ of $\mathrm{AUC}$ & $P$ value \\
\hline $\mathrm{Lac} / \mathrm{Cr}$ ratio in BG & $>0.38$ & $95(75.1-99.9)$ & $90.1(55.5-99.7)$ & 0.93 & $0.74-0.98$ & $<0.001^{*}$ \\
\hline $\mathrm{Lac} / \mathrm{Cr}$ ratio in thalamus & $>0.36$ & $80(56.3-94.3)$ & $100(69.2-100)$ & 0.94 & $0.78-0.99$ & $<0.001^{*}$ \\
\hline $\mathrm{Lac} / \mathrm{Cr}$ ratio in frontal WM & $>0.42$ & $85(62.1-96.8$ & $80(44.4-97.5)$ & 0.91 & $0.77-0.99$ & $<0.001^{*}$ \\
\hline Lac/Cr ratio occipital & $>0.42$ & $87(62.5-97)$ & $100(69.2-100)$ & 0.93 & $0.76-0.99$ & $<0.001^{*}$ \\
\hline NAA/Cr ratio in BG & $\leq 0.9$ & $90(68.3-98.8)$ & $90(55.5-99.7)$ & 0.91 & $0.75-0.98$ & $<0.001^{*}$ \\
\hline $\mathrm{NAA} / \mathrm{Cr}$ ratio in thalamus & $\leq 0.75$ & $80(56.5-94.5)$ & $92(95.5-99.7)$ & 0.93 & $0.78-0.99$ & $<0.001^{*}$ \\
\hline NAA/Cr ratio in frontal WM & $\leq 0.9$ & $95(75.1-99.9)$ & $70(34.8-93.3)$ & 0.90 & $0.74-.98$ & $<0.001^{*}$ \\
\hline $\mathrm{NAA} / \mathrm{Cr}$ ratio in occipital WM & $\leq 0.8$ & $90(68.3-98.8)$ & $80(44.4-97.5)$ & 0.82 & $0.64-0.93$ & $<0.001^{*}$ \\
\hline $\mathrm{NAA} /$ Cho ratio in $\mathrm{BG}$ & $\leq 0.29$ & $95(75.3-99.5)$ & $87(44.4-99.5)$ & 0.78 & $0.59-0.91$ & $<0.001^{*}$ \\
\hline NAA/Cho ratio in thalamus & $\leq 0.25$ & $80(56.3-94.3)$ & $89(45.5-99.9)$ & 0.86 & $0.69-0.96$ & $<0.001^{*}$ \\
\hline NAA/Cho ratio in frontal WM & $\leq 0.31$ & $95(75.1-99.9)$ & $80(44.4-97.5)$ & 0.80 & $0.61-0.92$ & $<0.001^{*}$ \\
\hline NAA/Cho ratio in occipital WM & $\leq 0.30$ & $95(75.1-99.9)$ & $75(54.4-98.5)$ & 0.79 & $0.59-0.91$ & $<0.001^{*}$ \\
\hline
\end{tabular}

*Significant at $\mathrm{p}<0.05$

These results also matches with Fan et al. [18] who studied MRI and MR spectroscopy in 38 full-term neonates suffered from HIE (9 neonates with Sarnat stage I, 13 Sarnat stage II and 16 stage III according to clinical signs and the presence of a history of asphyxia) and illustrated that the group whose $\mathrm{Lac} / \mathrm{Cr}$ ratio more than 1.5 had severe lesions detected by MRI and poor outcome and they concluded that MRS is a very useful tool in diagnosis patients with HIE and predicting their outcome.

In 1HMRS peak metabolites ratios: At the level of basal ganglia, Lac/Cr and NAA/Cho ratios had higher sensitivity 95 than NAA/Cr 90 while highest specificity was for $\mathrm{Lac} / \mathrm{Cr} 90.1$ versus NAA/Cr 90 then NAA/Cho 87. At the level of thalamus, each of $\mathrm{Lac} / \mathrm{Cr}, \mathrm{NAA} / \mathrm{Cr}$ and NAA/Cho ratios had equal sensitivity 80 , while $\mathrm{Lac} / \mathrm{Cr}$ ratio had higher specificity 100 versus NAA/Cr 92 then NAA/Cho 89. At the level of frontal white matter, NAA/ $\mathrm{Cr}$ and NAA/Cho showed higher sensitivity 95 than Lac/ $\mathrm{Cr}$ while Lac/Cr and NAA/Cho showed higher specificity 80 than NAA/Cr 70. At the level of occipital white matter NAA/Cho was the highest sensitivity 95 versus NAA/ $\mathrm{Cr}$ and $\mathrm{Lac} / \mathrm{Cr} 90$ and 87 while $\mathrm{Lac} / \mathrm{Cr}$ was the highest specificity 100 versus $\mathrm{NAA} / \mathrm{Cr}$ and NAA/Cho 80 and 75 , respectively. Lac/Cr ratio higher than $0.38,0.36,0.42$ in basal ganglia, thalamus and white matter was significantly predictive of pathological outcome. NAA/Cr ratio lower than $0.9,0.75,0.9,0.8$ in basal ganglia, thalamus, frontal and occipital white matter was significantly predictive of pathological outcome. NAA/Cho ratio lower than $0.29,0.25,0.31,0.3$ in basal ganglia, thalamus, frontal and occipital white matter was significantly predictive of pathological outcome.

The current study found that NAA/Cr and NAA/Cho were significantly lower in patients with poor outcome than patients with favorable outcome. This is in agreement with Lally et al. [21] who examined 223 neonates of whom 160 examined by MRS in a multi-centric cohort study to assess prognostic accuracy of MRS biomarkers as early predictors of the neurodevelopmental abnormalities observed years after neonatal encephalopathy and found that each of NAA/Cr, NAA/Cho, Lac/NAA and NAA concentration are specific and sensitive in predicting patient's outcome. Cutoff value of NAA/Cho within the thalamus was $<0.22$ (close to found in current result 0.25 ) showing significant correlation with poor outcome.

These results also are in consistent with Ancora et al. [7] who studied 20 full-term neonates with different stages of perinatal hypoxia and found that MR spectroscopy is an accurate early predictor for poor neurologic outcome in neonates as the difference of NAA/Cr, NAA/ Cho and Lac/NAA between normal neonates and others with pathological outcome was statistically significant. $\mathrm{NAA} / \mathrm{Cr}$ ratio $\leq 0.67$ within the basal ganglia (close to study's cutoff 0.75 in thalamus and 0.9 within basal ganglia) was significant of poor outcome.

There is disagreement with Guo et al. [4] who examined 24 neonates and found that MRS is a useful technique for distinguishing between HIE and normal newborns. However, with regard to differentiating between grades, MRS should be interpreted in conjunction with performances on T1WI in reverse to current study in which the differences of Lac/Cr, NAA/Cr and NAA/Cho ratios between mild, moderate and severe cases were statistically significant $(P=0.05)$. Also the ascent in $\mathrm{Lac} / \mathrm{Cr}$ ratio was not marked in contrast to present study. It seems likely that this difference of results is related to the time of the MRS examination with respect to the hypoxic-ischemic event. The mean time from injury to MRS in patients in the 
current study was 23 days; for patients in Guo et al. [4] was 7 days.

The present results proved that in all examined regions HIE stage III had significantly higher Lac/Cr ratio than stage II than stage I. This matches Thayyil et al. [11] who reviewed all studies that compared MR biomarkers performed during the neonatal period (including conventional MRI, DWI and MRS) with neurodevelopmental outcome at age of 1 year and found that MRS specifically $\mathrm{Lac} / \mathrm{NAA}$ and Lac/Cr ratio had better diagnostic accuracy than conventional MRI performed at any time during the neonatal period.

On the other hand, a larger recent study was done by Alderliesten et al. [8] who studied 88 neonates, 22 of whom died and 7 had unfavorable motor outcome. They documented that infants with poor outcome had obviously higher Lac/NAA ratios than infants with a normal outcome. This current study has relied on $\mathrm{Lac} / \mathrm{Cr}$ ratio in adverse to many studies which depended on Lac/NAA ratio as it is an unreliable index of Lac accumulation as NAA is often reduced in hypoxic-ischemic injury as mentioned by Cady [22]

At the level of parieto-occipital cortex and basal ganglia Ancora et al. [9] had examined 23 patients with mean age from 7 to 10 days and concluded that NAA/Cr and $\mathrm{Lac} / \mathrm{Cr}$ measured at parietal-occipital level were the best predictors of outcome. Cutoff value of $\mathrm{Lac} / \mathrm{Cr}>0.3$ (close to current study >0.42) at parietal-occipital level was able to discriminate between newborns that developed CP and those that did not until 2 years of age. Similar to this recent study which found that $\mathrm{Lac} / \mathrm{Cr}$ ratio was significantly higher in patients with poor outcome than patients with favorable outcome and that $\mathrm{NAA} / \mathrm{Cr}$ ratio was significantly lower in patients with poor outcome than patients with favorable outcome.

Other studies match current results as Shanmugalingam et al. [23] who studied 21 newborns with HIE and documented that compared with normal outcome, lactate/Cr and lactate/NAA were higher and NAA/Cr was lower in patients who had severe outcome and Cheong et al. [24] who studied the value of MRS in the thalamus in 17 newly born infants suffered from perinatal HIE and also concluded that $\mathrm{Lac} / \mathrm{Cho}, \mathrm{Lac} / \mathrm{Cr}$ and Lac/NAA in neonates with neonatal encephalopathy with severe outcome were all increased compared with control values and with those infants with normal or mild outcome. In addition, NAA/Cr and NAA/Cho in the severe outcome group were reduced compared with both control and normal or mild groups.

It was found that in all examined regions HIE stage III had significantly higher Lac/Cr ratio and lower NAA/Cr and NAA/Cho ratios than stage II than stage I. This is in agreement with Zhu et al. [19] who examined 46 patients to investigate the prognostic values of MRS obtained from neonatal brains with hypoxic-ischemic encephalopathy and found that, $\mathrm{Glx}-\mathrm{a} / \mathrm{Cr}$ and $\mathrm{Lac} / \mathrm{Cr}$ values were higher in the moderate and severe HIE groups than in the mild HIE group, whereas the NAA/Cho and NAA/Cr values in severe HIE group were much lower than in mild and moderate HIE. Additionally, there was positive correlation between the values of $\mathrm{Glx}-\mathrm{a} / \mathrm{Cr}$ and $\mathrm{Lac} / \mathrm{Cr}$ and the severity of brain injury. But there was a negative correlation between the values of NAA/Cr and NAA/Cho and the severity of brain injury in HIE (in current study glutamine was not measured by MRS machine).

The results in the present study were also consistent with those of the study of Barkovich et al. [25] in which patients experienced injury within an average of 7 days prior to MRS and found associations with NAA levels in HIE and a preliminary study of Cady [22] in which metabolite concentrations in neonates with neonatal encephalopathy documented increases in (Lac) and reductions in (NAA), (Cho), and (Cr) similar to those reported in this current study.

\section{Limitation}

For ethical reasons, there was no control group. Another limitation of this study is common to nearly all studies of neonatal encephalopathy, that precise time of injury was not known in most of the patients. The extent and pattern of injury vary temporally. Some areas will appear more severely injured and some less injured, depending on the timing of the scan with respect to the injury.

\section{Conclusion}

MRS in addition to MRI elevates the degree of confidence in diagnosis of HIE patients especially in mild and moderate cases, so it is recommended to be added to MRI examination.

High Lac/Cr, low NAA/Cr and low NAA/Cho ratios within examined regions of the brain including deep grey matter nuclei as well as white matter are associated with an adverse outcome in infants with perinatal asphyxia.

MRS is an accurate quantitative MR biomarker within the neonatal period for prediction of neurodevelopmental outcome after perinatal HIE.

MRS may be useful in early clinical management decisions, and counseling parents thereby ensuring appropriate early intervention and rehabilitation. 


\begin{abstract}
Abbreviations
MRI: Magnetic resonance imaging; MRS: Magnetic resonance spectroscopy; Lac: Lactate; Cr: Creatine; NAA: N-acetyl aspartate; Cho: Choline; GLX: Glutamate; HIE: Hypoxic ischemic encephalopathy; T1WI:T1-weighted images; T2WI: T2-weighted images; DWI: Diffusion-weighted images; FLAIR: Fluid attenuation inversion recovery; PVL: Periventricular leukomalacia; PLIC: Posterior Limb of Internal Capsule; ROC: Receiver operating characteristics; PRESS: Point resolved spectroscopy; MVS: Multiple voxel spectroscopy; CSI: Chemical shift imaging; MRSI: Magnetic resonance spectroscopic imaging.
\end{abstract}

\section{Acknowledgements}

To all the participants for their cooperation and patience.

\section{Authors' contributions}

ES suggested the research idea, ensured the original figures and data in the work, minimized the obstacles to the team of work, correlated the study concept and design and had the major role in analysis, MD supervised the study with significant contribution to design the methodology, manuscript revision and preparation. WE correlated the clinical data of patient and matched it with the findings, drafted and revised the work. FE collected data in all stages of manuscript, performed data analysis. All authors read and approved the final manuscript for submission.

\section{Funding}

No funding. Not applicable for this section.

\section{Availability of data and materials}

The author's confirm that all data supporting the finding of the study are available within the article and the raw data and data supporting the findings were generated and available at the corresponding author on request.

\section{Declarations}

\section{Ethics approval and consent to participate}

Written informed consent was obtained from all patients' guardiancies after full explanation of the benefits and risks of procedure, the study was approved by ethical committee of Tanta university hospital, faculty of medicine (32187/03/18)

\section{Consent for publication}

All participants included in the research gave written consent to publish the data included in the study. Authors accepted to publish the paper.

\section{Competing interests}

The authors declare that they have no competing of interests.

\section{Author details}

${ }^{1}$ Radiology Department, Faculty of Medicine, Tanta University, El-geish street, Tanta, Gharbya governorate, Egypt. ${ }^{2}$ Faculty of Medicine, Tanta University,

El-geish Street, Tanta, Gharbia governorate, Egypt.

Received: 9 May 2021 Accepted: 30 July 2021

Published online: 10 August 2021

\section{References}

1. Bano S, Chaudhary V, Garga UC (2017) Neonatal hypoxic-ischemic encephalopathy: a radiological review. J Pediatr Neurosci 12:1-6

2. Barta H, Jermendy A, Kolossvary M et al (2018) Prognostic value of early, conventional proton magnetic resonance spectroscopy in cooled asphyxiated infants. BMC Pediatr 18:302-313

3. Zou R, Xiong T, Zhang L et al (2018) Proton magnetic resonance spectroscopy biomarkers in neonates with hypoxic-ischemic encephalopathy: a systematic review and meta- analysis. Front Neurol 9:732-745
4. Guo L, Wang D, Bo G et al (2016) Early identification of hypoxic-ischemic encephalopathy by combination of magnetic resonance (MR): imaging and proton MR spectroscopy. Exp Ther Med 12:2835-2842

5. Jadas V, Brasseur-Daudruy M, Chollat C et al (2013) The contribution of the clinical examination, electroencephalogram, and brain MRI in assessing the prognosis in term newborns with neonatal encephalopathy. A cohort of 30 newborns before the introduction of treatment with hypothermia. Arch Pediatrics 21:125-133

6. Gano D, Chau V, Poskitt KJ et al (2013) Evolution of pattern of injury and quantitative MRI on days 1 and 3 in term newborns with hypoxic-ischemic encephalopathy. Pediatr Res 74:82-87

7. Ancora G, Testa C, Grandi S et al (2013) Prognostic value of brain proton MR spectroscopy and diffusion tensor imaging in newborns with hypoxicischemic encephalopathy treated by brain cooling. Neuroradiology 55(8):1017-1025

8. Alderliesten T, de Vries LS, Staats L et al (2017) MRI and spectroscopy in (near): term neonates with perinatal asphyxia and therapeutic hypothermia. Arch Dis Child Fetal Neonatal Ed 102(2):147-152

9. Ancora G, Soffritti S, Lodi R et al (2010) A combined a-EEG and MR spectroscopy study in term newborns with hypoxic-ischemic encephalopathy. Brain Develop 32:835-842

10. Van Doormaal PJ, Meiners LC, Ter Horst HJ et al (2012) The prognostic value of multivoxel magnetic resonance spectroscopy determined metabolite levels in white and grey matter brain tissue for adverse outcome in term newborns following perinatal asphyxia. Eur Radiol 22:772-778

11. Thayyil S, Chandrasekaran M, Taylor A et al (2010) Cerebral magnetic resonance biomarkers in neonatal encephalopathy: a meta-analysis. Pediatrics 125(2):382-395

12. Mansour Y, Hanfy D, Fathy S, Mohammed E (2017) Magnetic resonance imaging versus proton magnetic resonance spectroscopy in neonatal hypoxic ischemic encephalopathy in Egyptian population: pilot study. J Neurol Neurol Sci Disord 3(1):43-50

13. Alderliesten T, De Vries LS, Benders MJ et al (2011) MR imaging and outcome of term neonates with perinatal asphyxia: value of diffusion-weighted MR imaging and 1 H MR spectroscopy. Radiology 261:235-242

14. Sarnat HB, Sarnat MS (1976) Neonatal encephalopathy following fetal distress: a clinical and electroencephalographic study. Arch Neurol 9:696-705

15. Yu Y, Hsieh S, Hsu H, Chen C, Lee T, Chiu C, Jeng F (2013) A psychometric study of the Bayley Scales of Infant and Toddler Development-3rd Edition for term and preterm Taiwanese infants. Res Dev Disabil 34(11):3875-3883

16. Dopwell F, Maypole J, Sinha B, Currier H, DeBassio W, Augustyn M (2014) "More than meets the eye": when the neonatal course may impact several years out. J Dev Behav Pediatr 35(7):467-469

17. Agut T, Leon M, Rebollo M, Muchart J, Arca G, Garcia-Alix A (2014) Early identification of brain injury in infants with hypoxic ischemic encephalopathy at high risk for severe impairments: accuracy of MRI performed in the first days of life. BMC Pediatr 14:177

18. Fan G, Wu Z, Chen L et al (2003) Hypoxia-ischemic encephalopathy in fullterm neonate: correlation proton MR spectroscopy with MR imaging. Eur J Radiol 45(2):91-98

19. Zhu W, Zhong W, Jianpin Q et al (2008) Proton magnetic resonance spectroscopy in neonates with hypoxic-ischemic injury and its prognostic value. Transl Res 152(5):225-233

20. Noaman A, Elshafey R, Al-Shahawy A et al (2013) MR spectroscopy, S100B protein and NSE analysis as early predictors of hypoxic ishaemic encephalopathy. Egypt J Radiol Nucl Med 44(2):309-320

21. Lally PJ, Montaldo P, Oliveira V et al (2019) Magnetic resonance spectroscopy assessment of brain injury after moderate hypothermia in neonatal encephalopathy: a prospective multicentre cohort study. Lancet Neurol 18(1):35-45

22. Cady EB (1996) Metabolite concentrations and relaxation in perinatal cerebral hypoxic-ischemic injury. Neurochem Res 21(9):1043-1052

23. Shanmugalingam S, Thornton JS, Iwata O et al (2006) Comparative prognostic utilities of early quantitative magnetic resonance imaging spin-spin relaxometry and proton magnetic resonance spectroscopy in neonatal encephalopathy. Pediatrics 118(4):1467-1477 
24. Cheong JL, Cady EB, Penrice J et al (2006) Proton MR spectroscopy in neonates with perinatal cerebral hypoxic-ischemic injury: metabolite peak-area ratios, relaxation times, and absolute concentrations. AJNR Am J Neuroradiol 27(7):1546-1554

25. Barkovich AJ, Miller SP, Bartha A et al (2006) MR imaging, MR spectroscopy, and diffusion tensor imaging of sequential studies in neonates with encephalopathy. Am J Neuroradiol 27(3):533-547

\section{Publisher's Note}

Springer Nature remains neutral with regard to jurisdictional claims in published maps and institutional affiliations.
Submit your manuscript to a SpringerOpen ${ }^{0}$ journal and benefit from:

- Convenient online submission

- Rigorous peer review

- Open access: articles freely available online

- High visibility within the field

- Retaining the copyright to your article

Submit your next manuscript at $\boldsymbol{\nabla}$ springeropen.com 